\title{
Interfacial Reactions of Liquid Sn and Sn-3.5Ag Solders With Ag Thick Films
}

\author{
T.L. Su, L.C. Tsao, S.Y. Chang, and T.H. Chuang
}

(Submitted 28 March 2002)

\begin{abstract}
The interfacial reactions of liquid $\mathrm{Sn}$ and $\mathrm{Sn-3.5Ag}$ solders with $\mathrm{Ag}$ thick films are investigated in the temperature range from $250-325{ }^{\circ} \mathrm{C}$, and the morphology of intermetallic compounds formed after such soldering reactions is observed. In kinetics analysis of the growths of intermetallic compounds, it was found that both $\mathrm{Sn} / \mathrm{Ag}$ and $\mathrm{Sn}-3.5 \mathrm{Ag} / \mathrm{Ag}$ reactions were interfacial-controlled, and the growth rates for both cases were similar. The rate of Ag dissolution into liquid solder attendant on the formation of interfacial intermetallic compounds after $\mathrm{Sn} / \mathrm{Ag}$ reaction was about four times higher than that after $\mathrm{Sn}-3.5 \mathrm{Ag} / \mathrm{Ag}$ reaction, as evidenced by experimental results.
\end{abstract}

Keywords $\mathrm{Ag}$ dissolution, $\mathrm{Ag}_{3} \mathrm{Sn}$ intermetallic compound, $\mathrm{Ag}$ thick film, $\mathrm{Sn} / \mathrm{Ag}, \mathrm{Sn}-3.5 \mathrm{Ag} / \mathrm{Ag}$, soldering reactions

\section{Introduction}

In a previous work by the authors, the intermetallic compounds and their growth kinetics during the soldering reactions between liquid $\mathrm{Sn}$ and $\mathrm{Ag}$ plates were studied. ${ }^{[1]}$ The results showed that, along with the formation of $\mathrm{Ag}_{3} \mathrm{Sn}$ intermetallic compounds at $\mathrm{Sn} / \mathrm{Ag}$ interface, the $\mathrm{Ag}$ substrate dissolved severely into the molten solder. Typically, such an erosion phenomenon on the Ag substrate can be alleviated by the addition of the Ag element into the Sn solder, in which case the growth kinetics of interfacial intermetallic compounds will also be affected. Because Ag thick films have been widely used for the manufacturing of hybrid integrated circuits (HIC), resistors, ceramic capacitors, and multilayer chip inductors, it makes sense to conduct a further investigation of $\mathrm{Sn}$ and $\mathrm{Sn}-\mathrm{Ag}$ solders reacted with Ag thick films. For the present experimental investigation, a eutectic Sn-3.5Ag alloy was used, which has been recognized as one of the promising candidates for $\mathrm{Pb}$-free solders in the electronics industry. This study compared the growth kinetics of interfacial intermetallic compounds and dissolutions of $\mathrm{Ag}$ thick films between $\mathrm{Sn} / \mathrm{Ag}$ and $\mathrm{Sn}-3.5 \mathrm{Ag} / \mathrm{Ag}$ soldering reactions.

\section{Experimental}

For the preparation of the Ag thick film, the surface of an alumina substrate was coated with silver paste (composition: Ag 75-80 wt.\%, glass 1-5 wt.\%, resin 1-5wt.\%, Terpineol 5-10 wt.\% and Diethyl Phthalate 5-10 wt.\%) using a screen printer. Specimens were first heated at $150{ }^{\circ} \mathrm{C}$ for $10 \mathrm{~min}$ and then sintered at $850{ }^{\circ} \mathrm{C}$ for $10 \mathrm{~min}$ in an air furnace. After the specimens were sintered, they were cooled to room tempera-

T.L. Su, L.C. Tsao, S.Y. Chang, and T.H. Chuang, Department of Materials Science and Engineering, National Taiwan University, Taipei 106, Taiwan, China. Contact e-mail: tunghan@ccms.ntu.edu.tw. ture. The sintered Ag thick film on the alumina substrate possessed a thickness of $10 \mu \mathrm{m}$ and low porosity. The Sn-3.5Ag solder was prepared by vacuum melting into an ingot and homogenized at $100{ }^{\circ} \mathrm{C}$ for $50 \mathrm{~h}$. Afterward, both the $\mathrm{Sn}$ and $\mathrm{Sn}-3.5 \mathrm{Ag}$ solders were rolled into $0.2 \mathrm{~mm}$ thick foils. For the study of interfacial reactions, the solder foil was cut to the same size as the $\mathrm{Ag} / \mathrm{Al}_{2} \mathrm{O}_{3}$ substrate, placed on the $\mathrm{Ag} / \mathrm{Al}_{2} \mathrm{O}_{3}$ substrate, and then heated in an IR furnace under a vacuum of $10^{-3}$ torr. To eliminate the oxidation factor in soldering, a flux of SMQ TACFLUX 005 (Indium Co., Utica, NY) was applied before testing.

Soldering reactions took place at temperature ranging from $250-325{ }^{\circ} \mathrm{C}$ for various periods of time. After the reaction, the soldered specimens were cut along the cross section, ground with $\mathrm{SiC}$ paper, polished with 1 and $0.3 \mu \mathrm{m} \mathrm{Al}_{2} \mathrm{O}_{3}$ powders, and observed by scanning electron microscopy (SEM). For kinetics analysis, the thicknesses of intermetallic compounds were calculated by dividing the total areas of interfacial intermetallics by the widths of the intermetallics on the micrographs. The dissolved thickness $\left(X_{\mathrm{D}}\right)$ of the Ag thick film was estimated as follows: $X_{\mathrm{D}}=X_{\mathrm{I}}-X_{\mathrm{R}}-X_{I M}^{A g}=X_{\mathrm{I}}-X_{\mathrm{R}}-$ (3/4) $X_{\mathrm{IM}}$, where $X_{\mathrm{I}}$ is the initial thickness of the $\mathrm{Ag}$ thick film, $X_{\mathrm{R}}$ is the residual thickness of the Ag thick film, $X_{\mathrm{IM}}$ is the thickness of the interfacial intermetallic compound, and $X_{I M}^{A g}$ signifies the partial thickness of Ag in the intermetallic compound. The intermetallic compound in this study was $\mathrm{Ag}_{3} \mathrm{Sn}$ as analyzed by electron probe microanalysis (EPMA). The difference in atomic size between $\mathrm{Ag}$ and Sn notwithstanding, the partial thickness $\left(X_{I M}^{A g}\right)$ of the $\mathrm{Ag}$ thick film contained in the $\mathrm{Ag}_{3} \mathrm{Sn}$ intermetallic compound was about (3/4) $X_{\mathrm{IM}}$.

\section{Results and Discussion}

The typical micrographs of intermetallic compounds formed during interfacial reactions between liquid $\mathrm{Sn}$ and $\mathrm{Ag}$ thick films are shown in Fig. 1. It can be seen that the intermetallic compounds at the $\mathrm{Sn} / \mathrm{Ag}$ interface have a scallop-type morphology. EPMA analyses indicate that these interfacial intermetallic compounds are in the $\mathrm{Ag}_{3} \mathrm{Sn}$ phase. Through selective etching out of the $\mathrm{Sn}$ solder from the reacted $\mathrm{Sn} / \mathrm{Ag}$ specimens, 

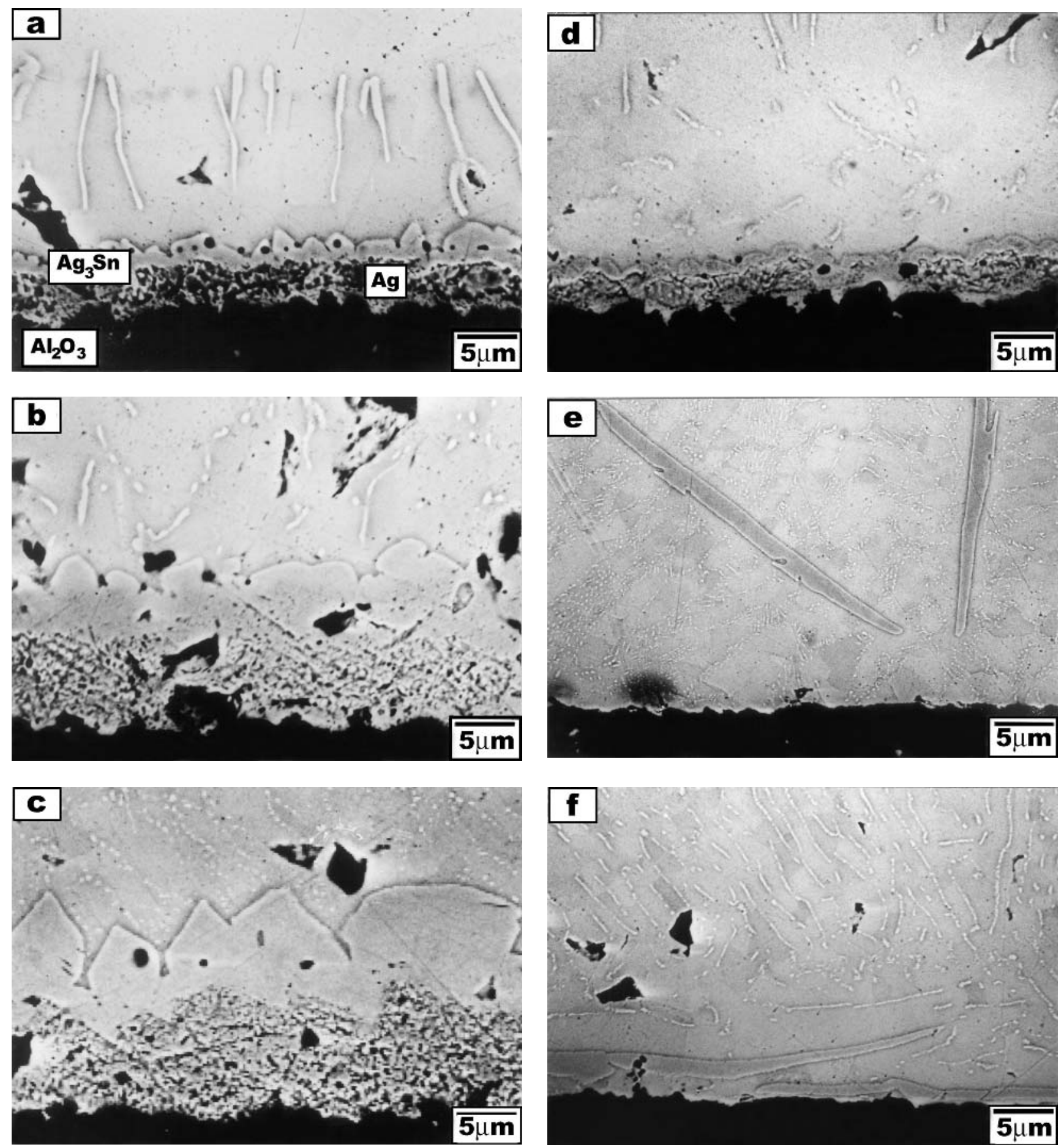

Fig. 1 Micrographs of the interfacial intermetallic compounds and matrix precipitates formed during soldering reaction between liquid Sn and the Ag thick film. (a) $250{ }^{\circ} \mathrm{C}, 20 \mathrm{~min}$. (b) $250{ }^{\circ} \mathrm{C}, 25 \mathrm{~min}$. (c) $250{ }^{\circ} \mathrm{C}, 30 \mathrm{~min}$. (d) $300{ }^{\circ} \mathrm{C}, 7 \mathrm{~min}$. (e) $300{ }^{\circ} \mathrm{C}, 15 \mathrm{~min}$. (f) $300{ }^{\circ} \mathrm{C}, 18 \mathrm{~min}$

the $\mathrm{Ag}_{3} \mathrm{Sn}$ phase is further confirmed by $\mathrm{x}$-ray diffractometry (XRD) to be present in the remaining intermetallic compounds, as shown in Fig. 2. The intermetallic compounds formed during the interfacial reactions of $\mathrm{Sn}$ thin film, and $\mathrm{Sn}-\mathrm{Pb}$ and $\mathrm{Sn}-\mathrm{Ag}$ solders with Ag substrates, have been reported in the literature to be in the $\mathrm{Ag}_{3} \mathrm{Sn}$ phase, ${ }^{[2-8]}$ which is consistent with the results of the current study.
Figure 1 illustrates that the Ag thick film dissolves into the pure Sn matrix for a distance of about $13 \mu \mathrm{m}$ after soldering reaction at $250{ }^{\circ} \mathrm{C}$ for $20 \mathrm{~min}$. The dissolved $\mathrm{Ag}$ atoms result in the formation of needle-like precipitates near the $\mathrm{Ag} / \mathrm{Sn}$ interface, which are also shown to be in the $\mathrm{Ag}_{3} \mathrm{Sn}$ phase as analyzed by EPMA. No $\mathrm{Ag}_{3} \mathrm{Sn}$ precipitates appear in the $\mathrm{Sn}$ matrix aside from this region. After the soldering reaction at 


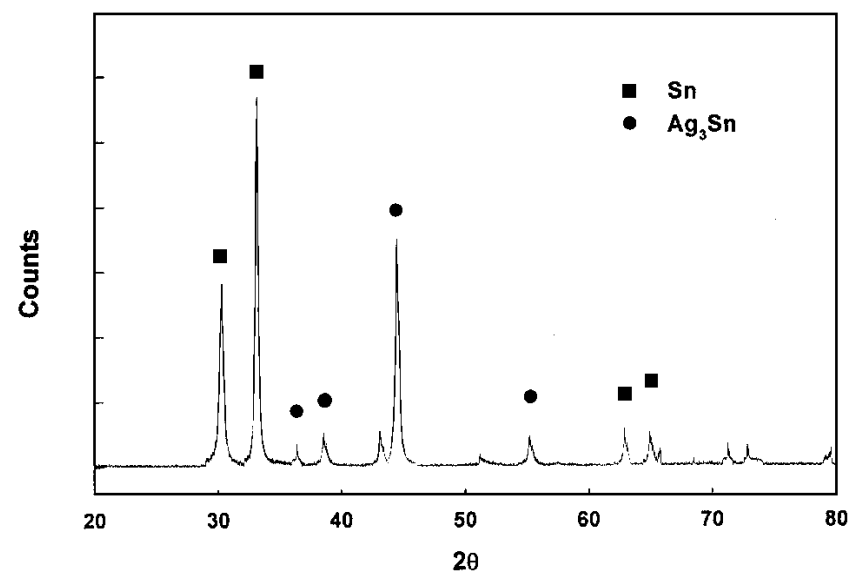

Fig. 2 Typical x-ray diffraction patterns of the intermetallic compounds formed at the interface between liquid $\mathrm{Sn}$ and $\mathrm{Ag}$ thick film after selectively etching out the Sn unreacted solder

$250{ }^{\circ} \mathrm{C}$ for $25 \mathrm{~min}$ or more, or as the reaction temperature is raised to above $275{ }^{\circ} \mathrm{C}$ for various time periods, the $\mathrm{Ag}_{3} \mathrm{Sn}$ precipitates are seen to distribute fully in the $\mathrm{Sn}$ matrix. In this case, the needle-like $\mathrm{Ag}_{3} \mathrm{Sn}$ precipitates are broken into particles located preferentially at grain boundaries of the $\mathrm{Sn}$ matrix. Figure 1 also shows that the residual Ag thick film has become porous after the soldering reaction. Such a porous structure of the remaining Ag thick film may be correlated to the severe dissolving of Ag Atoms through the grain boundaries of the sintered $\mathrm{Ag}$ thick film.

The micrographs in Fig. 1 also show that the scallop-shaped $\mathrm{Ag}_{3} \mathrm{Sn}$ intermetallic compounds at the $\mathrm{Sn} / \mathrm{Ag}$ interface grow with increasing reaction temperature and time. As the $\mathrm{Sn} / \mathrm{Ag}$ soldering reaction approaches the end, a number of large intermetallic bands appear in the Sn matrix, as shown in Fig. 1(e) and (f). EPMA analyses indicate that their compositions are the same as those of the interfacial $\mathrm{Ag}_{3} \mathrm{Sn}$ intermetallic compounds. From the Ag-Sn phase diagram, it can be seen that these large $\mathrm{Ag}_{3} \mathrm{Sn}$ intermetallic bands result from the decomposition of liquid solder bearing excessively dissolved $\mathrm{Ag}$ atoms into the $\mathrm{Ag}_{3} \mathrm{Sn}$ phase (intermetallic bands) and the eutectic phase $\left(\mathrm{Ag}_{3} \mathrm{Sn}\right.$ fine particles embedded in the Sn matrix) during the solidification process. However, a certain amount of intermetallic bands are found to settle along the $\mathrm{Sn} / \mathrm{Al}_{2} \mathrm{O}_{3}$ interface where the Ag thick film has been consumed (Fig. 1f). It seems that the $\mathrm{Ag}_{3} \mathrm{Sn}$ intermetallic bands have been preferentially formed ahead of the $\mathrm{Sn} / \mathrm{Al}_{2} \mathrm{O}_{3}$ interface prior to the conclusion of the $\mathrm{Sn} / \mathrm{Ag}$ soldering reaction. At that moment, the previously created scallop-shaped $\mathrm{Ag}_{3} \mathrm{Sn}$ intermetallic compounds are split away from the remainder of the thin Ag layer, which has been prone to dissolve exhaustively into the liquid Sn solder. The drastically increased $\mathrm{Ag}$ concentration in the liquid $\mathrm{Sn}$ solder ahead of the $\mathrm{Sn} / \mathrm{Al}_{2} \mathrm{O}_{3}$ interface results in the preferential decomposition of solder during the solidification process to form the intermetallic bands. These intermetallic bands will float away from the $\mathrm{Sn} / \mathrm{Al}_{2} \mathrm{O}_{3}$ interface into the liquid solder matrix because of their poor bonding with the $\mathrm{Al}_{2} \mathrm{O}_{3}$ ceramic substrate.

The morphology of the interfacial intermetallic compounds formed during the soldering reaction between liquid $\mathrm{Sn}-3.5 \mathrm{Ag}$
Table 1 Thicknesses of Interfacial Intermetallic Compounds Under Various Conditions (a)

\begin{tabular}{lrcccc}
\hline $\boldsymbol{T},{ }^{\circ} \mathbf{C}$ & $\boldsymbol{t}, \boldsymbol{m i n}$ & $\boldsymbol{X}_{\mathbf{I M}}, \boldsymbol{\mu m}$ & $\boldsymbol{X}_{\mathbf{R}}, \boldsymbol{\mu m}$ & $\boldsymbol{X}_{\boldsymbol{I M} \boldsymbol{M}}^{\boldsymbol{A g}}, \boldsymbol{\mu m}$ & $\boldsymbol{X}_{\mathbf{D}}, \boldsymbol{\mu m}$ \\
\hline 250 & 20 & 2.2 & 4.8 & 1.7 & 3.5 \\
250 & 25 & 4.8 & 4.1 & 3.6 & 2.3 \\
250 & 30 & 6.6 & 3.2 & 5.0 & 1.8 \\
275 & 9 & 2.3 & 3.2 & 1.7 & 5.0 \\
275 & 15 & 5.4 & 2.8 & 4.0 & 3.2 \\
275 & 20 & 7.0 & 1.0 & 5.2 & 3.4 \\
300 & 7 & 1.6 & 3.2 & 1.2 & 5.6 \\
325 & 5 & 2.8 & 1.6 & 2.1 & 6.4
\end{tabular}

(a) The thicknesses of residual Ag thick Films $\left(X_{\mathrm{R}}\right)$, created intermetallic compounds $\left(X_{\mathrm{IM}}\right)$, dissolved $\mathrm{Ag}$ thick films $\left(X_{\mathrm{D}}\right)$, and the partial thickness of $\mathrm{Ag}$ in the created intermetallic compounds $\left(X_{I M}^{A g}\right)$ after soldering reactions between liquid $\mathrm{Sn}$ and $\mathrm{Ag}$ thick films at various temperatures $(T)$ for various times $(t)$

Table 2 Thicknesses of Interfacial Intermetallic Compounds Under Various Conditions

\begin{tabular}{lccccc}
\hline $\boldsymbol{T},{ }^{\circ} \mathbf{C}$ & $\boldsymbol{t}, \boldsymbol{m i n}$ & $\boldsymbol{X}_{\mathbf{I M}}, \boldsymbol{\mu m}$ & $\boldsymbol{X}_{\mathbf{R}}, \boldsymbol{\mu m}$ & $\boldsymbol{X}_{\boldsymbol{I M}}^{\boldsymbol{A g}}, \boldsymbol{\mu m}$ & $\boldsymbol{X}_{\mathbf{D}}, \boldsymbol{\mu m}$ \\
\hline 250 & 20 & 2.4 & 7.9 & 1.3 & 0.2 \\
250 & 28 & 4.6 & 5.7 & 3.4 & 0.8 \\
250 & 32 & 5.6 & 5.6 & 4.2 & 0.3 \\
275 & 20 & 2.5 & 6.3 & 1.9 & 1.8 \\
275 & 24 & 4.7 & 5.7 & 3.5 & 0.8 \\
275 & 28 & 5.5 & 5.3 & 4.2 & 0.6 \\
300 & 12 & 4.8 & 5.7 & 3.6 & 0.7
\end{tabular}

(a) The thicknesses of residual $\mathrm{Ag}$ thick films $\left(X_{R}\right)$, created intermetallic compounds $\left(X_{\mathbf{I M}}\right)$, dissolved $\mathrm{Ag}$ thick films $\left(X_{D}\right)$, and the partial thickness of $\mathrm{Ag}$ in the created intermetallic compounds $\left(X_{I M}^{A g}\right)$ after soldering reactions between liquid $\mathrm{Sn}-3.5 \mathrm{Ag}$ and $\mathrm{Ag}$ thick films at various temperatures $(T)$ for various times $(t)$

and Ag thick films (shown in Fig. 3) is similar to that during the $\mathrm{Sn} / \mathrm{Ag}$ soldering reaction. In both cases, there are also similar appearances of precipitates in the solder matrix. However, the precipitate-free region at the early stage of $\mathrm{Sn} / \mathrm{Ag}$ soldering reaction (Fig. 1a) cannot be found with the $\mathrm{Sn}-3.5 \mathrm{Ag} / \mathrm{Ag}$ reaction (Fig. 3a), which indicates that most of the precipitates formed in the latter case have originated from the Ag alloying element contained in the $\mathrm{Sn}-3.5 \mathrm{Ag}$ solder. It also results in a thicker residual $\mathrm{Ag}$ thick film after $\mathrm{Sn}-3.5 \mathrm{Ag} / \mathrm{Ag}$ soldering reaction at $250{ }^{\circ} \mathrm{C}$ for $20 \mathrm{~min}$ (Fig. 3a) as compared with the $\mathrm{Sn} / \mathrm{Ag}$ reaction (Fig. 1a). In addition, the structural porosity of the remaining $\mathrm{Ag}$ thick film after $\mathrm{Sn} / \mathrm{Ag}$ soldering reaction can obviously be alleviated for the $\mathrm{Sn}-3.5 \mathrm{Ag} / \mathrm{Ag}$ reaction (Fig. 3). At the final stage of the $\mathrm{Sn}-3.5 \mathrm{Ag} / \mathrm{Ag}$ soldering reaction, the floating of large intermetallic bands can also be observed (Fig. $3 e, f)$. Figure 3(e) gives a strong indication that such floating intermetallic bands have been stripped from the solder $/ \mathrm{Al}_{2} \mathrm{O}_{3}$ substrate interface.

The thicknesses of the interfacial intermetallic compounds $\left(X_{\mathrm{IM}}\right)$ formed during the soldering reactions of liquid $\mathrm{Sn}$ and $\mathrm{Sn}-3.5 \mathrm{Ag}$ with $\mathrm{Ag}$ thick films under various conditions are summarized in Tables 1 and 2 . The data are plotted against the 

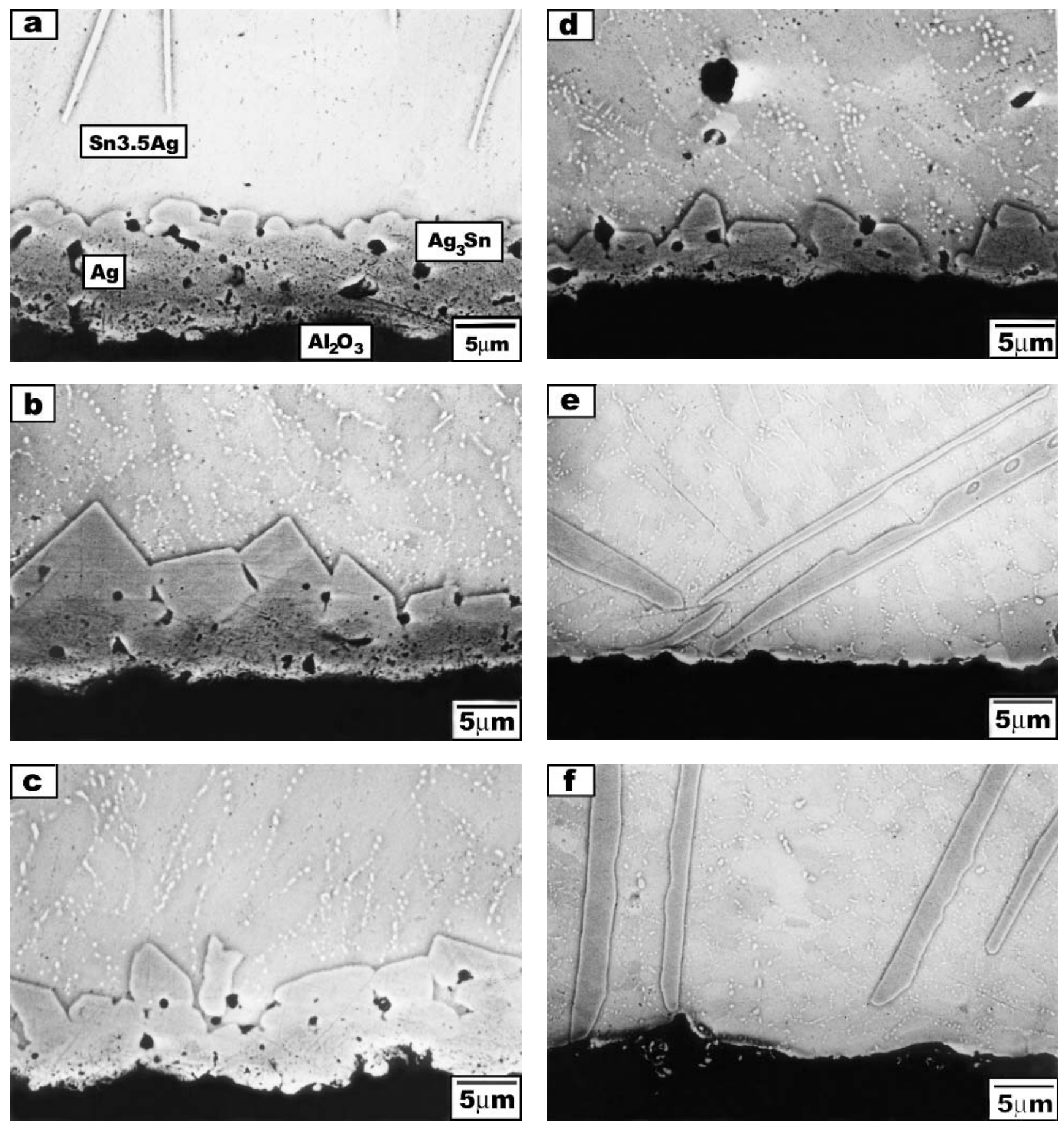

Fig. 3 Micrographs of the interfacial intermetallic compounds and matrix precipitates formed during soldering reaction between liquid Sn-3.5Ag and the $\mathrm{Ag}$ thick film. (a) $250{ }^{\circ} \mathrm{C}, 20 \mathrm{~min}$. (b) $250{ }^{\circ} \mathrm{C}, 28 \mathrm{~min}$. (c) $250{ }^{\circ} \mathrm{C}, 32 \mathrm{~min}$. (d) $300{ }^{\circ} \mathrm{C}, 12 \mathrm{~min}$. (e) $300{ }^{\circ} \mathrm{C}, 16 \mathrm{~min}$. (f) $300{ }^{\circ} \mathrm{C}, 20 \mathrm{~min}$

reaction time as shown in Fig. 4. For each soldering temperature in this study, there were fewer than three reliable measurements obtained because the as-sintered Ag thick film possesses only a thickness of $10 \mu \mathrm{m}$. Despite insufficient data for kinetics analysis, the plots in Fig. 4 are approximately linear, which implies that the growths of interfacial intermetallic compounds during both reactions of $\mathrm{Sn}$ and $\mathrm{Sn}-3.5 \mathrm{Ag}$ solders with Ag thick films are interface-controlled. However, in our pre- vious study on the interfacial reaction between liquid $\mathrm{Sn}$ solder and $\mathrm{Ag}$ plates, the growth kinetics of $\mathrm{Ag}_{3} \mathrm{Sn}$ intermetallic compounds was shown to be diffusion-controlled. ${ }^{[1]}$ Such a discrepancy also appeared in our previous studies on the interfacial reactions of In49Sn solder with $\mathrm{Ag}$ plates $^{[9]}$ and Ag thick films. ${ }^{[10]}$ This type of linear growth kinetics of the intermetallic compounds should be attributed to the penetration of liquid solder through the interfacial glass phase between the sintered 


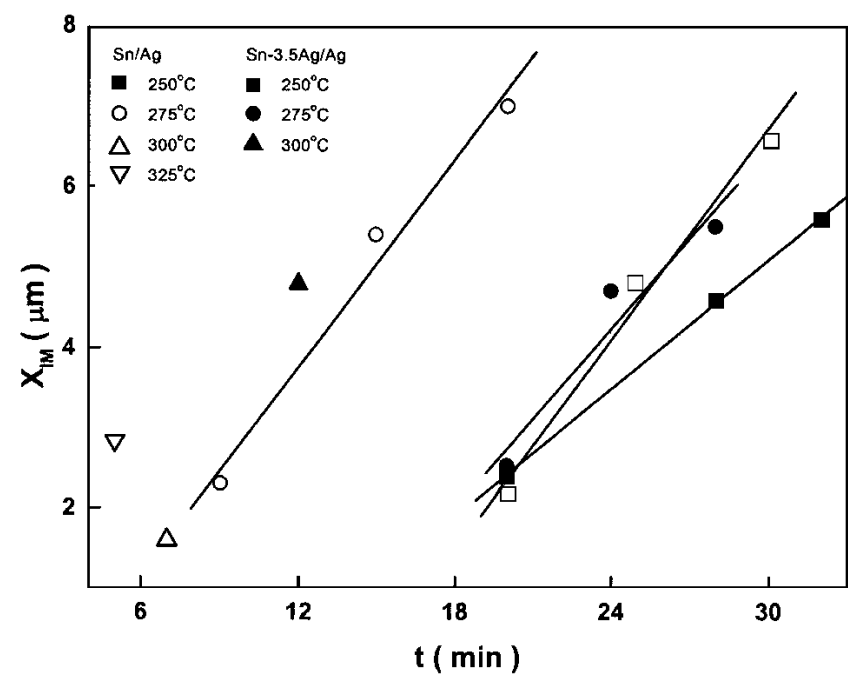

Fig. 4 The thickness of interfacial intermetallic compounds $\left(X_{\mathrm{IM}}\right)$ formed during soldering reactions of liquid $\mathrm{Sn}$ and $\mathrm{Sn}-3.5 \mathrm{Ag}$ with $\mathrm{Ag}$ thick films as a function of reaction time $(t)$

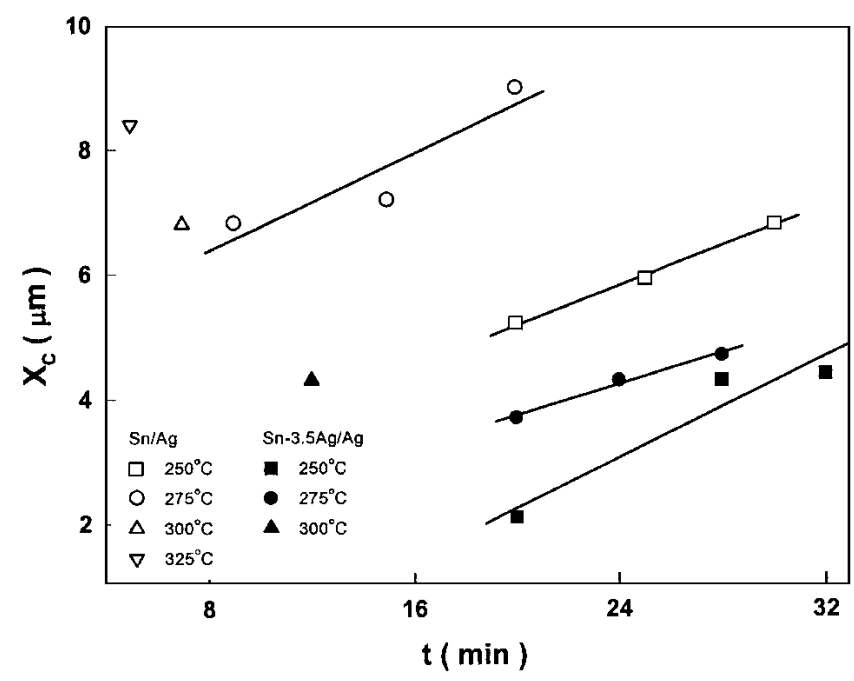

Fig. 5 The thickness of consumed Ag thick films $\left(X_{\mathrm{c}}=X_{\mathrm{I}}-X_{\mathrm{R}}\right)$ after soldering reactions of liquid $\mathrm{Sn}$ and $\mathrm{Sn}-3.5 \mathrm{Ag}$ with $\mathrm{Ag}$ thick films as function of reaction time. ( $X_{\mathrm{I}}$ and $X_{\mathrm{R}}$, respectively, signify the $\mathrm{Ag}$ thick film in its original and residual forms.)

$\mathrm{Ag}$ grains. The penetrated liquid solder reacts with the $\mathrm{Ag}$ grains at their interfaces, which results in an interfacial controlled growth of the intermetallic compounds. From Fig. 4, it can also be seen that the growth rates of interfacial intermetallic compounds during the $\mathrm{Sn} / \mathrm{Ag}$ and $\mathrm{Sn}-3.5 \mathrm{Ag} / \mathrm{Ag}$ soldering reactions are similar.

From Fig. 1 and 3, it can be observed that accompanying the formation of interfacial intermetallic compounds, a large amount of precipitates appear in the solder matrix. For the $\mathrm{Sn} / \mathrm{Ag}$ reaction, such precipitates in the Sn matrix should result from the dissolution of $\mathrm{Ag}$ atoms from $\mathrm{Ag}$ thick films into liquid Sn solder. In fact, the dissolution of the Ag substrate during the $\mathrm{Sn} / \mathrm{Ag}$ soldering reaction has been evidenced through marking the original $\mathrm{Sn} / \mathrm{Ag}$ interface with a Ta thin film. ${ }^{[1]}$ Even for the Sn-3.5Ag solder reacted with the Ag thick film, further dissolutions of $\mathrm{Ag}$ atoms into the liquid solder are inevitable, though basically the situation can be mitigated to a certain degree. To compare the dissolution of the Ag thick film during the $\mathrm{Sn} / \mathrm{Ag}$ soldering reaction with that during the $\mathrm{Sn}$ $3.5 \mathrm{Ag} / \mathrm{Ag}$ reaction, the residual thicknesses of $\mathrm{Ag}$ thick films $\left(X_{\mathrm{R}}\right)$ in both cases are measured and listed in Tables 1 and 2. The difference between the initial thickness $\left(X_{\mathrm{I}}\right)$ and the residual thickness $\left(X_{\mathrm{R}}\right)$ of $\mathrm{Ag}$ thick films gives the thickness $\left(X_{\mathrm{C}}\right)$ of $\mathrm{Ag}$ thick films consumed after the soldering reactions. Consistent with the growth rate analysis in Fig. 4, the plots for the consumed thickness of Ag thick films as shown in Fig. 5 are also governed by a linear relation.

Because the consumed Ag thick films are used in part to form the interfacial intermetallic compounds and in part to dissolve into the liquid solder, the dissolution amounts of $\mathrm{Ag}$ thick films $\left(X_{\mathrm{D}}\right)$ can be obtained by subtracting the residual $\mathrm{Ag}$ thickness $\left(X_{\mathrm{R}}\right)$ and the partial $\mathrm{Ag}$ thickness in the created $\mathrm{Ag}_{3} \mathrm{Sn}$ intermetallic compounds $\left(X_{I M}^{A g}\right)$ from the initial Ag thickness $\left(X_{\mathrm{I}}\right)$. It has been known that the lattice size of $\mathrm{Ag}(a=$ $4.086 \AA)$ is near that of $\operatorname{Sn}(a=5.831 \AA, c=3.181 \AA)$. The partial $\mathrm{Ag}$ thickness in the $\mathrm{Ag}_{3} \mathrm{Sn}$ intermetallic compounds $\left(X_{I M}^{A g}\right)$ can thus be roughly estimated as $(3 / 4) X_{\mathrm{IM}}$. In Tables 1 and 2, the $X_{\mathrm{D}}$ values are also shown for $\mathrm{Sn} / \mathrm{Ag}$ and $\mathrm{Sn}-3.5 \mathrm{Ag} /$ $\mathrm{Ag}$ soldering reactions. It is obvious that the dissolution amounts of $\mathrm{Ag}$ thick films during the $\mathrm{Sn} / \mathrm{Ag}$ reaction are about four-fold larger than those during the $\mathrm{Sn}-3.5 \mathrm{Ag} / \mathrm{Ag}$ reaction. In principle, the decrease of the residual Ag thickness $\left(\Delta X_{R}\right)$ accompanied by a sequential increase in time $(\Delta t)$ for the soldering at a definite reaction temperature cannot be lower than the increase of the partial Ag thickness in the intermetallic compounds $\left(X_{I M}^{A g}\right)$ if all of the Ag atoms in the newly grown intermetallic compounds have originated from the consumed $\mathrm{Ag}$ thick films. To the contrary, Tables 1 and 2 show evidence that $X_{I M}^{A g}$ is often greater than $\Delta X_{\mathrm{R}}$, which implies that part of the $\mathrm{Ag}$ atoms dissolved into the solder might have turned back to join in the growth of the interfacial intermetallic compounds.

\section{Conclusions}

During the soldering reactions of $\mathrm{Sn}$ and $\mathrm{Sn}-3.5 \mathrm{Ag}$ with $\mathrm{Ag}$ thick films, scallop-shaped $\mathrm{Ag}_{3} \mathrm{Sn}$ intermetallic compounds appear at their interfaces. Attendant on the growth of such interfacial intermetallic compounds, needle-like precipitates are formed in the solder matrix and then transformed into fine particles to be distributed along the grain boundaries of the solders. At the final stage of soldering reactions, a number of large $\mathrm{Ag}_{3} \mathrm{Sn}$ intermetallic bands can be observed in the solder matrix. Kinetic analyses show that the growth of interfacial intermetallic compounds during the $\mathrm{Sn} / \mathrm{Ag}$ and $\mathrm{Sn}-3.5 \mathrm{Ag} / \mathrm{Ag}$ soldering reactions are interface-controlled and the growth rates for both cases are similar. The appearance of precipitates in the $\mathrm{Sn}$ matrix during $\mathrm{Sn} / \mathrm{Ag}$ soldering reaction gives evidence of the Ag dissolution in the Sn solder, which also occurs to the $\mathrm{Sn}-3.5 \mathrm{Ag} / \mathrm{Ag}$ reaction. However, the dissolution rate of $\mathrm{Ag}$ during $\mathrm{Sn} / \mathrm{Ag}$ reaction is about four times higher than that during the $\mathrm{Sn}-3.5 \mathrm{Ag} / \mathrm{Ag}$ reaction. 


\section{References}

1. T.L. Su, L.C. Tsao, S.Y. Chang, and T.H. Chuang: "Morphology and Growth Kinetics of $\mathrm{Ag}_{3} \mathrm{Sn}$ During Soldering Reaction Between Liquid $\mathrm{Sn}$ and an Ag Substrate," J. Mater. Eng. Perform., 2002, 11(4), pp. 365-68.

2. V. Simic and Z. Marinkovic: "Room Temperature Interactions in AgMetals Thin Film Couples," Thin Solid Films, 1979, 61(2), pp. 149-60.

3. Z. Marinkovic and V. Simic: "Kinetics of Reaction at RoomTemperature in Thin Silver Metal Couples," Thin Solid Films, 1991, 195(1-2), pp. 127-35.

4. V. Simic and Z. Marinkovic: "Stability of Compounds in Thin-Film Metal Couples in the Course of Long Aging at Room Temperature," Thin Solid Films, 1992, 209(2) pp. 181-97.

5. X.H. Wang and H. Conrad: "Effect of Sn Content of Pb-Sn Solder Alloys on Wetting Dynamics," Scr. Metal. Mater., 1994, 31(4), pp. 375-80.
6. C.J. Thwaites and M. Woodall: "Silver-Palladium Metallisation Interactions With Reflowed Solder Pastes," Brazing Soldering, 1987, 12, pp. 57-60.

7. Y. Moriya, Y. Yamade, and R. Shinya: "Interface Reaction Between Ag-Pd Conductor and Pd-Sn Solder," IEEE Trans. CPMT B, 1998, 21(4), pp. 394-97.

8. G.Y. Li and Y.C. Chan: "Interactions Between Silver-Palladium Metallization Tin-Lead-Silver Solder," Phys. Stat. Sol., 1998, 166(2), pp. R13-R14

9. Y.T. Huang and T.H. Chuang: "Interfacial Reactions Between Liquid In-49Sn Solders and Ag Substrates," Z. Metallkd., 2000, 91, pp. 100205.

10. M.D. Cheng, S.S. Wang, and T.H. Chuang: "Soldering Reactions Between In49Sn and Ag Thick Films," J. Electron. Mater., 2002, 31(3), pp. 171-77. 